\title{
MEDIO AMBIENTE, GONSTITUGIÓN Y TRATADOS EN CHILE
}

\author{
ENVIRONMENT, CONSTITUTION AND TREATIES IN CHILE
}

\author{
Liliana GALDAMEZ ZELADA**
}

RESUMEN: En materia ambiental, además de un derecho fundamental, la Constitución chilena contiene deberes de protección y una cláusula de restricción de derechos. La configuración normativa de la cuestión ambiental en la Constitución establece una protección fuerte del medio ambiente que, sin embargo, en la práctica ha resultado debilitado. Partiendo de unas características diferentes, algo similar ocurre con los tratados internacionales en materia ambiental.

Palabras clave: Medio ambiente libre de contaminación; protección del paisaje; conservación del patrimonio ambiental; deberes de protección
ABSTRACT: In environmental matters, apart from a fundamental right, the Chilean Constitution includes protection obligations and a restriction-of-rights clause. The normative configuration of the environment issue in the Constitution establishes a strong protection of the environment that, in practice, appears weakened. Albeit from different characteristics, it similarly occurs with environment-related international treaties.

Keywords: pollution-free environment, landscape protection, environmental heritage conservation, protection obligations.

* Artículo recibido el 22 de octubre de 2015 y aceptado para su publicación el 23 de mayo de 2016.

**Doctora en derecho, investigadora en el Centro de Derechos Humanos, Facultad de Derecho Universidad de Chile, lgaldamez@derecho.uchile.cl.

Este trabajo se enmarca en el Proyecto Fondecyt de iniciación: Estudio sobre los derechos y obligaciones que reconoce y asume el Estado chileno en materia ambiental desde una perspectiva constitucional, No 1140270, del que la autora es investigadora principal.

Boletín Mexicano de Derecho Comparado nueva serie, año XLX, núm. 148, enero-abril de 2017, pp. 113-144.

D. R. (C) 2017. UNAM, Instituto de Investigaciones Jurídicas. 
Esta revista forma parte del acervo de la Biblioteca Jurídica Virtual del Instituto de Investigaciones Jurídicas de la UNAM

SUMARIO: I. Introducción. II. El medio ambiente sometido a presión y la Constitución. III. El medio ambiente en la historia de la Constitución de 1980. IV. El medio ambiente como derecho, deber de protección y cláusula de restricción de derechos. V. Medio ambiente y tratados ratificados en Chile. VI. Reflexiones finales.

VII. Bibliografia.

\section{INTRODUCCIÓN}

En el siglo XXI el medio ambiente se ha convertido en una zona marcada por tensiones y conflictos. Si bien la crisis ecológica, especialmente presente en las preocupaciones de la comunidad de naciones desde el informe The Limits to Growth de 1972, a finales del siglo XX, los países de economías emergentes, que llevan años procurando mejorar las condiciones de vida de sus habitantes, empiezan a evidenciar que muchos de sus avances han comprometido otros bienes esenciales para ese bienestar, la calidad del entorno, el acceso al agua, la conservación de la biodiversidad y la protección de sus paisajes naturales.

En este sentido, para Boaventura de Sousa Santos, "La promesa de la dominación de la naturaleza se llevó a cabo de una manera perversa al destruir la naturaleza misma y generar la crisis económica". ${ }^{1}$

Si bien tradicionalmente desde el derecho administrativo se ha abordado la cuestión ambiental para su regulación, la lógica del derecho constitucional establece una particularísima relación con el entorno. Al derecho constitucional le interesa el medio ambiente porque ha pasado a ser un asunto de interés público, de relevancia constitucional. De ello dan cuenta la mayoría de las Constituciones, que han ido incorporando referencias a su protección y al reconocimiento de derechos fundamentales asociados. $^{2}$

1 De Sousa Santos, Boaventura, El milenio huérfano, Bogotá, Trotta Ilsa, 2005, p. 37.

2 En América Latina: Argentina, artículos 41 y 43; Bolivia, artículos 8o., 9o., 30, 33 , 34, 80, 108, 135, 136, 189, 255, 298, 299, 302, 304, 312, 316, 337, 342, 343, 344, 345, 346, $347,348,349,350,351,352,353,354,355,356,357,358,380,381,382$, 383, 385, 386, 387, 388, 389, 390, 391 y 392; Brasil, artículos 5o., 23, 24, 129, 170, 174, 186, 200, 220 у 225; Colombia, artículos 67, 78, 79, 88, 95, 268, 277, 289, 300, 310, 317, 331, 333, 334 y 361; Costa Rica, artículos 46 y 50; Ecuador, artículos 14, 15, 27, 32, 66, 74, 83, 258, 267 , 276, 323, 326, 347, 376, 385, 387, 391, 395, 396, 397, 398, 399, 400, 401, 402, 403, 404, 405, 406, 407, 408, 409, 41 1, 412, 413 y 414; México, artículos 4, 25, 73 y 122; Perú, artículos 2o., 3o., 192 y 195; Venezuela, artículos 15, 112, 127, 128, 129, 156, 178, 184 y 29.

D. R. C 2017. UNAM, Instituto de Investigaciones Jurídicas,

Boletin Mexicano de Derecho Comparado, núm. 148, pp. 113-144. 
Esta revista forma parte del acervo de la Biblioteca Jurídica Virtual del Instituto de Investigaciones Jurídicas de la UNAM

Tal ha sido el impacto del medio ambiente, que Constituciones como la ecuatoriana reconocen a la naturaleza la titularidad de derechos fundamentales. Así lo señala Ramiro Ávila Santa María, "La Constitución de Ecuador, pionera en la ruptura de la concepción tradicional de derechos humanos, reconoce por primera vez el derecho de la naturaleza como un derecho autónomo del ser humano". ${ }^{3}$

El tratamiento de la cuestión ambiental en la Constitución chilena de 1980, visto con detención, no sólo es garantista, sino especialmente protector del entorno. ${ }^{4}$ No obstante - en mi opinión-, la norma no ha desplegado toda su fuerza normativa.

\section{EL MEDIO AMBIENTE SOMETIDO A PRESIÓN Y LA CONSTITUGIÓN}

El Instituto Nacional de Derechos Humanos de Chile publicó en 2012 un informe que identifica un total de 97 conflictos socioambientales registrados entre enero de 2010 y junio de 2012, informe que en una versión actualizada en 2015 eleva la cifra a 102. ${ }^{5}$ Una tipología con relación a sus temáticas nos muestra que estos conflictos se relacionan con proyectos mineros; centrales termoeléctricas; contaminación por partículas como el plomo; extracción ilegal de aguas; contaminación de ríos; extracción de oro, cultivo de peces en pisciculturas; uso de transgénicos; pesca y explotación de litio, entre otros.

Así, en el caso de pozos de extracción de aguas en el Parque Nacional del Lauca, señala el informe:

3 Ávila Santa, María Ramiro, "El derecho de la naturaleza: fundamentos", Repositorio Institucional del Organismo Académico de la Comunidad Andina CAN N, Universidad Andina Simón Bolívar, 2010, p. 22.También la Constitución de Bolivia reconoce a la madre tierra como titular de derechos en su artículo 33.

4 En este sentido, afirma Jorge Bermúdez, "La densidad de la normativa constitucional ambiental chilena supera con creces a lo que acontece en el derecho constitucional comparado". Bermúdez, Soto, Jorge, Fundamentos de derecho ambiental, 2a. ed., Valparaíso, Ediciones Universitarias de Valparaíso-Pontificia Universidad Católica de Valparaíso, 2015, p. 114.

5 El informe sobre "Mapa de conflictos socioambientales en Chile" de 2015, publicado por el INDH, se encuentra disponible en http://wrere.indh.cl/indh-presenta-nueva-versiondel-mapa-de-conflictos-socioambientales-en-chile.

D. R. (C) 2017. UNAM, Instituto de Investigaciones Jurídicas, Boletín Mexicano de Derecho Comparado, núm. 148, pp. 113-144. 
Esta revista forma parte del acervo de la Biblioteca Jurídica Virtual del Instituto de Investigaciones Jurídicas de la UNAM

La gran cantidad de vegetación altiplánica y la presencia de pumas, vicuñas, llamas, guanacos, ñandúes y flamencos chilenos hicieron que UNESCO decretara la zona como Reserva de la Biosfera en 1981. Durante muchos años este parque ha estado sometido a presiones por parte de los sectores productivos minero y agrícola, que buscan utilizar las riquezas minerales y el agua que hay en esta zona. ${ }^{6}$

La geógrafa Marcela Palominos-Schalsca retrata desde la ecología nuestra realidad:

Chile constituye uno de los primeros y más radicales experimentos en la aplicación de políticas neoliberales alrededor del mundo. El neoliberalismo ha impactado dramáticamente en el modelo económico de desarrollo, y, en forma sobresaliente, ha influido en las relaciones políticas respecto a la naturaleza y a los pueblos indígenas. ${ }^{7}$

El principal objetivo de este trabajo será examinar el tratamiento de la cuestión ambiental en la Constitución vigente y sus principales aportes para la protección del medio ambiente, mientras que las claves para comprender por qué en la práctica la protección del entorno ha resultado debilitado será un asunto que intentaré explicar en el apartado sobre reflexiones finales,

El constituyente de 1980 concibió, en la vanguardia de los ochenta, incorporar en el artículo 19, numeral 8, de la Constitución, un derecho: el derecho a vivir en un medio ambiente libre de contaminación, deberes de protección y una cláusula de limitación de derechos. Además, el recurso de protección garantiza el derecho, "cuando... sea afectado por un acto u omisión ilegal imputable a una autoridad o persona determinada".

El sentido y alcance del artículo 19, número 8, se ha construido a golpe de jurisprudencia, y su análisis doctrinario ha sido elaborado más desde el derecho regulatorio, particularmente desde la Ley 19.300 sobre Bases del Medio Ambiente, que desde la Constitución. Cabe señalar, en este sentido, que desde distintas perspectivas la ley a que he hecho refe-

6 Mapa de Conflictos Socioambientales en Chile, Instituto Nacional de Derechos Humanos, p. 13, http://bibliotecadigital.indh.cl/bitstream/handle/123456789/478/mapa-conflictos.pdf ? sequence $=4$.

7 Palomino-Schalscha, Marcela, "Ejercitando poder en tiempos neoliberales: resistencia, comodificación y emprendimiento en Alto Biobío", Ecología y política en Chile. Naturaleza, propiedad, conocimiento y poder, Santiago, Editorial Universitaria, 2015, p. 213.

D. R. (C) 2017. UNAM, Instituto de Investigaciones Jurídicas,

Boletin Mexicano de Derecho Comparado, núm. 148, pp. 113-144. 
Esta revista forma parte del acervo de la Biblioteca Jurídica Virtual del Instituto de Investigaciones Jurídicas de la UNAM

rencia, rebaja el contenido iusfundamental del derecho, por ejemplo, a propósito de la definición de lo que entiende como medio ambiente libre de contaminación; ${ }^{8}$ derecho que por otra parte cede constantemente ante la libertad de empresa y el derecho de propiedad.

En cuanto este último aspecto, el muy reciente informe elaborado por la OCDE, Evaluación del Desempeño Ambiental de Chile de 2016, señala:

Chile ha mejorado sustancialmente los niveles de vida y una serie de grandes inversiones ampliaron el acceso de la población a servicios clave, como el tratamiento de las aguas residuales y el transporte público urbano. No obstante, este crecimiento sólido se vio acompañado de una tenaz persistencia de la desigualdad de los ingresos y de mayores presiones sobre el medio ambiente, sobre todo la contaminación atmosférica, la escasez de agua, la pérdida de hábitats, y la contaminación del agua y el suelo... Muchas regiones de Chile revisten importancia significativa para la diversidad biológica mundial, pero se mantiene la intensidad de las presiones que las actividades económicas y el desarrollo de la infraestructura ejercen en los ecosistemas. ${ }^{9}$

En medio del proceso constituyente, recientemente anunciado, es imprescindible revisar aquellas materias que requieren ser actualizadas de cara a la futura Constitución. No puedo dejar de recordar que la constitución chilena de 1980 viene dando claras señales de desgaste. ${ }^{10}$

8 Una crítica a la definición de la noción medio ambiente libre de contaminación en la Ley 19.300 ha sido planteada por Humberto Nogueira cuando señala: "Consideramos que la disposición precedente citada debió referirse a niveles de contaminantes que afectaren la calidad ambiental dentro de la cual se encuentra la vida y calidad de vida de las personas y no a un riesgo de la salud, ya que la protección de la salud se encuentra asegurada como derecho fundamental autónomo en otra disposición del artículo 19 de la Carta Fundamental, a ello debemos agregar que la cantidad de contaminantes que se requieren para afectar la calidad ambiental de vida de las personas que es lo que protege el artículo 19, núm. 8 exige una regla más estricta que aquella que pueda afectar la salud de las personas asegurada por el artículo 19, núm. 9, la cual puede soportar mayores niveles de contaminación". Véase Nogueira, Humberto, "Revista Jurídica Justicia Ambiental. Revista de Derecho Ambiental de la Fiscalía del Medio Ambiente (FIMA)", Revista Estudios Constitucionales, Santiago, año 7 núm. 2, 2009, p. 470.

9 Comisión Económica para América Latina y el Caribe (CEPAL)-Organización para la Cooperación y el Desarrollo Económicos (OCDE), Evaluaciones del desempeño ambiental: Chile 2016, Santiago, 2016, p. 4.

10 Sobre esta materia véase Galdamez Zelada, Liliana, "La relación entre el derecho internacional de los derechos humanos y el derecho interno en el ordenamiento chileno

D. R. (C) 2017. UNAM, Instituto de Investigaciones Jurídicas, Boletín Mexicano de Derecho Comparado, núm. 148, pp. 113-144. 
Esta revista forma parte del acervo de la Biblioteca Jurídica Virtual del Instituto de Investigaciones Jurídicas de la UNAM www.juridicas.unam.mx

\section{EL MEDIO AMBIENTE EN LA HISTORIA DE LA CONSTITUGIÓN}

DE 1980

El artículo 19 de la Constitución señala:

La constitución asegura a todas las personas:

8o. El derecho a vivir en un medio ambiente libre de contaminación. Es deber del Estado velar para que este derecho no sea afectado y tutelar la preservación de la naturaleza.

La ley podrá establecer restricciones específicas al ejercicio de determinados derechos o libertades para proteger el medio ambiente.

La naturaleza de las normas constitucionales requiere de una constante actividad interpretativa. A pesar de los múltiples debates y enfoques en la doctrina a propósito de los límites de la interpretación, ${ }^{11}$ alguna actividad interpretativa debe ser aplicada cuando se trata de enfrentar a la norma a una situación concreta.

La formulación normativa de los derechos y deberes de protección medioambientales en la Constitución chilena de 1980 tiene la estructura de un principio, ${ }^{12}$ esto es, "mandatos de optimización de un determinado valor o bien jurídico... normas que ordenan que el valor o bien jurídico por ellas contemplado sea realizado en la mayor medida posible". ${ }^{13}$

Además de su nomenclatura en clave de principio y las dificultades que ello supone, su estudio conlleva otro desafío. Nociones como medio ambiente libre de contaminación y deber del Estado de tutelar la preservación de la naturaleza, nos redireccionan a conceptos que provienen de otras ciencias, que requieren ser dotados de significado. Identificarlos es complejo, por los múltiples matices en las definiciones de las nociones en juego. ${ }^{14}$

y la Constitución material", en Nogueira, Humberto (coord.), Bases de la institucionalidad realidad y desafios, Santiago, Librotecnia, 2015, pp. 79-88.

11 Sobre la polémica a propósito de la interpretación del derecho, $c f r$. Rodríguez, Puerto, Manuel Jesús, Interpretación, derecho ideología. La aportación de la hermenéutica jurídica, Granada, Comares, 2011, p. 102.

12 Alexy, Robert, Epílogo a la Teoría de los derechos fundamentales, Madrid, Centro de Estudios Constitucionales, 1993, p. 22.

13 Diez-Picazo, Luis, Sistema de derechos fundamentales, Navarra, Arazadi, 2005, p. 44.

14 Estenssoro Saavedra, Fernando, Historia del debate ambiental en la política mundial, 1945 1992, La perspectiva latinoamericana, Santiago de Chile, Instituto de Estudios Avanzados, Uni-

D. R. (C) 2017. UNAM, Instituto de Investigaciones Jurídicas,

Boletin Mexicano de Derecho Comparado, núm. 148, pp. 113-144. 
Esta revista forma parte del acervo de la Biblioteca Jurídica Virtual del Instituto de Investigaciones Jurídicas de la UNAM

Beatriz Bustos, Manuel Prieto y Jonathan Barton, en un interesante y reciente trabajo sobre ecología política en Chile (2015), señalan que

Cronon (1996) identificó al menos ocho maneras de pensar la naturaleza: la naturaleza como realidad ingenua, como imperativo moral, como edén, como artificio consciente de sí mismo, como artefacto cultural, como realidad virtual, como mercancía, como otro-demoniaco, o como terreno impugnado. En este sentido, Cronon (1996) sostiene que la realidad de la naturaleza es innegable, pero el hecho de que escape a nuestro universo lingüístico la hace incapturable y, al mismo tiempo, objeto de disputa y conflicto. Cada una de estas formas de entender la naturaleza está asociada a definiciones de acceso control y uso. Con ello se abren nuevas líneas de comprensión sobre cómo los discursos asociados a la naturaleza son empleados para controlar comunidades, generar consentimiento y disciplina ambiental. ${ }^{15}$

Desde esta perspectiva, la naturaleza fue pensada por la Comisión Ortúzar, encargada de elaborar el anteproyecto constitucional que luego se convertiría en la Constitución de 1980, como una realidad ingenua y como imperativo moral.

Sin ánimo de defender una interpretación originalista de la norma, es interesante revisar las discusiones de la Comisión, porque se distancian del clivaje asociado a la crisis institucional que vivió Chile en 1973. Ajenos a la discusión sobre la reconstrucción de la democracia desde el liberalismo y respeto al derecho de propiedad, se distingue otra perspectiva ideológica, esta vez a propósito de la cuestión ambiental. Se trata de una fuerte inclinación por la protección del medio ambiente, defensa que para los comisionados estaba implícita en el artículo 1o. de la Constitución, en la noción bien común.

Es en el acta 186, del 9 de marzo de 1976, donde se desarrolla la parte gruesa de la discusión. Fue el comisionado Sergio Diez quien propuso abordar cuestiones ambientales.

La cuestión ambiental no se incorporó en el capítulo I sobre Bases de la Institucionalidad, por estar implícita en la noción bien común. Con

versidad de Santiago, 2014, p. 61. Sobre las diversas definiciones contenidas en La ley 19.300 sobre Bases del Medio Ambiente y su apartado de definiciones, cfr. Astorga Jorquera, Eduardo, Derecho ambiental. Parte general, Santiago, Abeledo-Perrot-Legal PublishingThompson Reuters, 2012, p. 47.

15 Bustos, Beatriz et al., Ecología política en Chile. Naturaleza, propiedad, conocimiento y poder, Santiago de Chile, Editorial Universitaria, 2015, p. 23 . 
Esta revista forma parte del acervo de la Biblioteca Jurídica Virtual del Instituto de Investigaciones Jurídicas de la UNAM

relación a la noción bien común, señaló el profesor Alejandro Silva Bascuñán:

Dentro de esa idea, si el bien común consiste en proporcionar a todos los habitantes - personas naturales o morales - las condiciones necesarias para su integral desarrollo humano, es un aspecto integrante, básico y genérico del mismo aquello de que el Estado deba asegurar a los habitantes, precisamente, un ambiente libre de toda contaminación, velar porque ese derecho no sea afectado y tutelar la preservación de los recursos naturales. De manera que esa disposición debe estar en el capítulo de las normas generales, precisamente porque expresa el ideal básico de la Constitución...

\section{Medio ambiente como derecho fundamental: habia que garantizarlo}

No obstante, las prevenciones planteadas por el profesor Silva Bascuñán y Jaime Guzmán, en la Comisión se impuso la tesis de incluir al medio ambiente en el capítulo de los derechos. Así lo sostuvo Enrique Ortúzar cuando dijo que "...no ve inconveniente alguno para que el medio ambiente figure como garantía fundamental... en el supuesto de que no existieran disposiciones legales sobre la materia, con el solo mérito de esta garantía constitucional podría obtener de los tribunales de justicia reconocimientos". ${ }^{16}$

En la Comisión, el medio ambiente se consagra como como derecho teniendo a la vista la necesidad de garantizarlo. Además, y pese a opiniones divergentes, se le reconoce como derecho individual.

\section{Deber del Estado de tutelar la preservación de la naturaleza}

Sobre el significado del término "naturaleza" (originalmente se habló de recursos naturales, pero luego se optó por la noción naturaleza), Enrique Ortúzar dijo: “....se entiende, en términos generales y amplios, la tierra, el agua, el aire, la flora, la fauna, etcétera...". ${ }^{17}$

Respecto al límite sobre otros derechos fundamentales, especialmente al derecho de propiedad para proteger el medio ambiente, señaló Jaime

16 República de Chile, "Actas Oficiales de la Comisión Constituyente", sesión 186, del 9 de marzo de 1976, t. V, http://wrere.bcn.cl/lc/cpolitica/actas_oficiales-r.

17 Idem.

D. R. (C) 2017. UNAM, Instituto de Investigaciones Jurídicas,

Boletin Mexicano de Derecho Comparado, núm. 148, pp. 113-144. 
Esta revista forma parte del acervo de la Biblioteca Jurídica Virtual del Instituto de Investigaciones Jurídicas de la UNAM

Guzmán “...si se quiere proteger efectivamente el equilibrio ecológico, las riquezas naturales, el derecho del chileno a vivir en un ambiente libre de contaminación, corresponde dar al legislador la posibilidad de que, fundado en esos valores, establezca restricciones al ejercicio de determinadas garantías constitucionales...". ${ }^{18}$

\section{EL MEDIO AMBIENTE COMO DERECHO, DEBER DE PROTECGIÓN Y CLÁUSULA DE RESTRICGIÓN DE DEREGHOS}

Fernando Simón Yarza ${ }^{19}$ propone una sistematización sobre la incorporación del ambiente desde la perspectiva del derecho comparado, cuyas categorías parece oportuno seguir. En la Constitución, el medio ambiente ha sido tratado como mandato de protección; derecho social; deber constitucional; cláusula de restricción de derechos; como catálogo de derechos y deberes; además de existir textos sin previsiones sobre la protección ambiental. ${ }^{20}$

La Constitución chilena desarrolla tres de las categorías que he mencionado: ${ }^{21}$

Mandato de protección. En Europa, siguen esta consagración la Constitución alemana - artículo 20 de la Ley Fundamental-, que incorpora a través de una reforma del 27 de octubre de 1994 al artículo 20 a:

[Protección de los fundamentos naturales de la vida y de los animales] El Estado protegerá, teniendo en cuenta también su responsabilidad con las generaciones futuras, dentro del marco del orden constitucional, los fundamentos naturales de la vida y los animales a través de la legislación y, de acuerdo con la ley y el Derecho, por medio de los poderes ejecutivo y judicial.

De la misma manera, en Italia, el artículo 9o. de la Constitución consagra la tutela del paisaje: "La República promoverá el desarrollo de la

\footnotetext{
18 Idem.

19 Simón Yarza, Fernando, Medio ambiente y derechos fundamentales, Madrid, Centro de Estudios Políticos y Constitucionales, 2012, p. 26.

20 También en la doctrina nacional se ha asumido esta perspectiva en el tratamiento de la cuestión ambiental en la Constitución. Cfr. Bermúdez, Soto, Jorge, Fundamentos de derecho ambiental, 2a. ed., Ediciones Universitarias de Valparaíso, Pontificia Universidad Católica de Valparaíso, 2015, p. 114.

21 En el mismo sentido, Bermúdez Soto, op. cit., p. 113.
}

D. R. (C) 2017. UNAM, Instituto de Investigaciones Jurídicas, Boletín Mexicano de Derecho Comparado, núm. 148, pp. 113-144. 
Esta revista forma parte del acervo de la Biblioteca Jurídica Virtual del Instituto de Investigaciones Jurídicas de la UNAM www.juridicas.unam.mx

cultura y la investigación científica y técnica. Salvaguardará el paisaje y el patrimonio histórico y artístico de la Nación". ${ }^{22}$

En el caso de América Latina, esta fórmula se encuentra, por ejemplo, en la Constitución chilena (artículo 19, núm. 8) (deber del Estado de tutelar la preservación de la naturaleza), y en la Constitución del Ecuador (artículo 3o.). También la Constitución de la República Bolivariana de Venezuela asume este deber de protección (capítulo IX "De los derechos ambientales", artículo 127). En el mismo sentido, la Constitución de Costa Rica en el artículo 50.

Cláusula de restricción de derechos. Se trata de enunciados que, tal como se expresa en la Constitución chilena, habilitan al legislador para introducir limitaciones al ejercicio de otros derechos para proteger el medio ambiente, o bien que reconocen límites al ejercicio de determinados derechos para asegurar su protección; por ejemplo, la propiedad y la libertad de trabajo.

Medio ambiente como catálogo de derechos y deberes. En este sentido, por ejemplo, la Constitución de Ecuador, en el artículo 13, incorpora derechos ambientales. Para el caso europeo, uno de los más interesantes es el francés; allí, en junio de 2004 se incorpora la Carta del Medio Ambiente a su preámbulo. La Carta incorpora derechos, deberes individuales, deber de preservar y mejorar el medio ambiente y otras obligaciones relevantes. ${ }^{23}$ Sin embargo, el valor de las normas contenidas en ese Preámbulo es el de principios del ordenamiento, y no son considerados como derechos de la misma fuerza y naturaleza que los del catálogo de derechos fundamentales.

Es en Latinoamérica donde los poderes constituyentes han sido más entusiastas a la hora de reconocer derechos fundamentales asociados al medio ambiente, llegando incluso a reconocer a la naturaleza como sujeto de derechos fundamentales. ${ }^{24}$

22 Simón Yarza, op. cit, p. 37.

23 Carta del Medio Ambiente, Francia, "El pueblo francés, Considerando: Que los recursos y los equilibrios naturales han condicionado la emergencia de la humanidad... Proclama lo siguiente: Artículo 10. Cada uno tiene el derecho de vivir en un medio ambiente equilibrado y respetuoso de la salud; Artículo 20. Toda persona tiene el deber de participar en la preservación y la mejora del medio ambiente; Artículo 3o. Toda persona debe, en las condiciones definidas por la ley, prevenir las alteraciones que es susceptible de provocar en el medio ambiente o, en su defecto, limitar sus consecuencias...".

24 Ávila Santa, María Ramiro, "El derecho de la naturaleza: fundamentos", Repositorio Institucional del Organismo Académico de la Comunidad Andina CAN N, Universidad Andina Simón Bolívar, 2010.

D. R. (C) 2017. UNAM, Instituto de Investigaciones Jurídicas, Boletin Mexicano de Derecho Comparado, núm. 148, pp. 113-144. 
Esta revista forma parte del acervo de la Biblioteca Jurídica Virtual del Instituto de Investigaciones Jurídicas de la UNAM

La crítica del ambiente como derecho individual se basa en la estructura de los derechos como defensa; esto implica que existe un coto vedado al Estado, donde éste no puede intervenir. ¿Aplicaría esta perspectiva al medio ambiente? ¿Puede el Estado obligarse a reconocer un límite cuando hablamos de medio ambiente? Es sumamente difícil poder responder afirmativamente a esta pregunta. Tampoco sería posible identificar las excepciones al deber de no invadir el derecho, más en nuestro ordenamiento, que impone al Estado un deber de tutelar la preservación de la naturaleza. Es esta dificultad la que impediría configurar al ambiente como un derecho individual y de defensa. ${ }^{25}$

Para el caso chileno, si bien en la Comisión Ortúzar se plantearon dudas sobre la pertinencia de configurar al medio ambiente libre de contaminación como derecho fundamental, esas dudas se superaron y así se incorporó.

\section{Medio ambiente como mandato de protección: principio preventivo y la protección del paisaje}

La perspectiva del medio ambiente como un objeto de protección por parte del Estado, expresamente consagrada en la G.80, es un campo sumamente interesante para explorar.

En la Constitución chilena es posible reconocer tres mandatos constitucionales de protección en materia ambiental: ${ }^{26}$

1. El Estado debe velar para que el derecho no se vea afectado;

2. El Estado tiene el deber de proteger el medio ambiente (de manera independiente al ejercicio de derechos fundamentales);

3. El Estado tiene el deber de tutelar la preservación de la naturaleza.

Los derechos fundamentales no sólo son una barrera; también imponen un deber de actuación. Para Díez Picazo, lo interesante de esta relación radica en la manera de articular técnicamente una obligación positiva. El Estado está obligado a crear estructuras que concreten la efi-

25 Sobre esta crítica $c f r$. Simón Yarza, op. cit., pp. 46 y ss.

26 También Jorge Bermúdez trabaja la noción de protección ambiental, que contiene la Constitución. Cfr. Bermúdez, op. cit., pp. 174 y ss.

D. R. (C) 2017. UNAM, Instituto de Investigaciones Jurídicas, Boletín Mexicano de Derecho Comparado, núm. 148, pp. 113-144. 
Esta revista forma parte del acervo de la Biblioteca Jurídica Virtual del Instituto de Investigaciones Jurídicas de la UNAM

cacia de los derechos fundamentales. No es una novedad que los derechos fundamentales impliquen un deber de actuación, lo novedoso es que la Constitución incorpore un deber de protección explícito. ${ }^{27}$ A continuación, propongo algunas nuevas perspectivas que me parece derivan de los deberes de protección que la Constitución consagra:

\section{A. El Estado debe velar para que el derecho no se vea afectado: la consagración del principio preventivo en la Constitución}

Dada la naturaleza del bien jurídico protegido: medio ambiente, el Estado está particularmente obligado a velar - ex ante - a generar condiciones para que éste no se vea afectado. La dificultad que se identifica en este deber, es que no existen remedios jurisdiccionales para exigir al Estado su cumplimiento. Así, por ejemplo, para Bermúdez, "desde la perspectiva de los ciudadanos, uno de los graves problemas que han presentado los deberes constitucionales que pesan sobre los órganos del Estado radica en la forma en que estos pueden actualizarse en acciones concretas y positivas". ${ }^{28}$

Este deber implica crear institucionalidad y condiciones normativas, que aseguren que el derecho no se vea vulnerado. El deber de protección opera, en mi opinión, como un principio que actúa antes que se produzca la vulneración del derecho. Este deber de protección contribuye a establecer una protección reforzada del medio ambiente y conlleva la consagración del principio preventivo.

Sobre este principio, señala Pilar Moraga: "La Corte Internacional de Justicia considera al principio preventivo como (el deber de diligencia) que tiene cada Estado sobre su territorio, el cual se operacionaliza a través de la evaluación de impacto ambiental". ${ }^{29}$

27 Díez Picazo, Luis, Sistema de derechos fundamentales, Navarra, Arazadi, 2005.

28 Ibidem, p. 181.

29 Moraga, Pilar, "Análisis de la aplicación principio precautorio en el marco jurídico chileno", en Moraga, Pilar et al., El principio precautorio en el derecho comparado, Santiago de Chile, LOM, 2015, p. 23. También Eduardo Astorga lo define como "aquel en virtud del cual se han desarrollado la mayoría de los instrumentos de gestión ambiental. Y es obvio, resulta más eficaz y eficiente para la gestión ambiental prever eventuales menoscabos o detrimentos, que posteriormente restaurarlos o repararlos". Astorga Jorquera, Eduardo, op. ct., p. 14 .

D. R. (C) 2017. UNAM, Instituto de Investigaciones Jurídicas,

Boletin Mexicano de Derecho Comparado, núm. 148, pp. 113-144. 
Esta revista forma parte del acervo de la Biblioteca Jurídica Virtual del Instituto de Investigaciones Jurídicas de la UNAM

Dicho lo anterior, este principio no ha sido sistemáticamente sostenido por la doctrina y la jurisprudencia.

\section{B. El deber de protección del medio ambiente y principio preventivo}

La consagración del deber de protección del medio ambiente también supone la incorporación del principio preventivo a que hacíamos referencia, pero ahora con una particularidad. Lo que se protege es el entorno, independientemente de si ello acarrea la vulneración del derecho fundamental.

Tampoco en este caso existen remedios constitucionales para asegurar este deber. El principio preventivo que consagra la norma debe actuar como un elemento inspirador para legislador, para el juez y para todos los poderes del Estado, con objeto de que sus decisiones sean tomadas previendo eventuales consecuencias nocivas para el medio ambiente.

\section{Deber de tutelar la preservación de la naturaleza}

El deber de tutelar la preservación de la naturaleza se dirige a la protección de los elementos naturales del entorno. Como señala Guzmán Rosen, "se trata de proteger, sólo uno de los componentes del ambiente, excluyéndose a los artificiales y socio culturales". ${ }^{30}$

Ésta es una de las cláusulas más enigmáticas de la Constitución, a propósito de la cuestión ambiental. ¿Qué significa "preservar la naturaleza"? Según la RAE, "preservar" es "Proteger, resguardar anticipadamente a alguien o algo, de algún daño o peligro". ${ }^{31}$

Nuevamente aparece la consagración constitucional del principio preventivo. Esto implica que los órganos del Estado deben valorar los riesgos que su actuación puede acarrear para la naturaleza.

30 Guzmán Rosen, Rodrigo, La regulación constitucional del ambiente en Chile. Aspectos sustantivos y adjetivos. Historia, doctrina y jurisprudencia, Santiago de Chile, Abeledo-Perrot, 2010, p. 100.

31 Por su parte, para la Ley 19.300, preservación de la naturaleza es, artículo 2o. p): "el conjunto de políticas, planes, programas, normas y acciones, destinadas a asegurar la mantención de las condiciones que hacen posible la evolución y el desarrollo de las especies y de los ecosistemas del país". Mientras que desde la perspectiva de la ecología se le define como "protección, conservación y mantenimiento de una zona o categoría de seres vivos, de algún daño o peligro", Diccionario de ecología, Buenos Aires, Valleta Ediciones, 2010, p. 206.

D. R. (C) 2017. UNAM, Instituto de Investigaciones Jurídicas, Boletín Mexicano de Derecho Comparado, núm. 148, pp. 113-144. 
Esta revista forma parte del acervo de la Biblioteca Jurídica Virtual del Instituto de Investigaciones Jurídicas de la UNAM

En esta materia existe alguna jurisprudencia que ha acogido recursos de protección por la amenaza que determinadas acciones representan para la naturaleza:

Así si se contamina o se amenaza con aquello, se destruye la naturaleza, con lo cual, se agotan los recursos renovables y el ecosistema pierde su capacidad de regenerarse o de cumplir sus funciones principales en los procesos biofísicos, por lo que el presente arbitrio constitucional deberá ser acogido en este sentido. ${ }^{32}$ Sin embargo, como bien señala Pilar Moraga, esta aplicación no ha sido exenta de críticas, tanto porque se considera que el principio preventivo carece de consagración normativa como porque la doctrina ha entendido que los argumentos de los jueces se construyen desde el principio precautorio, "en nombre del principio preventivo". ${ }^{33}$

La obligación de tutelar la preservación de la naturaleza que pesa sobre el Estado y sus órganos (Ejecutivo, Legislativo y Poder Judicial), en mi opinión implica, además, la tutela del paisaje.

\section{La protección del paisaje}

Si bien la tutela constitucional del paisaje tampoco ha sido sistemáticamente sostenida en la doctrina y la jurisprudencia nacionales, dicha tutela se refuerza a la luz del artículo 19, núm. 24, inc. 2, de la Constitución, que a propósito del derecho de propiedad señala: "Sólo la ley puede establecer el modo de adquirir la propiedad, de usar, gozar y disponer de ella y las limitaciones y obligaciones que deriven de su función social. Esta comprende cuanto exijan los intereses generales de la Nación, la seguridad nacional, la utilidad y la salubridad públicas y la conservación del patrimonio ambiental". ¿Qué entendemos por "paisaje”? Para el Diccionario de ecología, paisaje es "aspecto que ofrece una parte de la superficie terrestre". ${ }^{34}$

\footnotetext{
32 Rol 5.339-2013, Corte Suprema.

33 Moraga, Pilar, op. cit., p. 23.

34 Diccionario de ecología, cit., p. 195. En cuanto a la definición jurídica de "paisaje”, Fernández Rodríguez (2007) afirma: "el paisaje objeto de protección jurídico administrativa ha de ser aquel que, en base a su consideración de bien jurídico digno de protección, lo fuera en todas y cada una de sus dimensiones: culturales, históricas, estéticas, medioambientales y territoriales". Fernández Rodríguez, Carmen, La protección del paisaje. Un estudio de derecho español y comparado, Madrid, Marcial Pons, 2007, p. 58.
}

D. R. (C) 2017. UNAM, Instituto de Investigaciones Jurídicas, Boletin Mexicano de Derecho Comparado, núm. 148, pp. 113-144. 
Esta revista forma parte del acervo de la Biblioteca Jurídica Virtual del Instituto de Investigaciones Jurídicas de la UNAM

También en la Comisión Ortúzar, sus integrantes consideraron la protección del patrimonio artístico y cultural, y el paisaje, y si consideramos que los elementos que integran la naturaleza la tierra, el agua, el aire, la flora, la fauna, en conjunto dan lugar al paisaje, no se ve cómo sería posible separar y desconectar esos elementos cuando nos referimos a paisajes de especial relevancia y riqueza.

Por otra parte, al momento de redactarse la Constitución, esta obligación ya había sido asumida por el Estado de Chile cuando ratificó la Convención para la Protección de la Flora, la Fauna y las Bellezas Escénicas Naturales de América, promulgada el 23 de agosto de 1967, también llamada Convención de Washington. Según la Convención, artículo V, 2, "Los Gobiernos Contratantes convienen en adoptar el recomendar a sus respectivos cuerpos legislativos la adopción de leyes que aseguren la protección y conservación de los paisajes, las formaciones geológicas extraordinarias, y las regiones y los objetos naturales de interés estético o valor científico o histórico".

La Convención contribuiría a delimitar los paisajes especialmente protegidos, aquellos valiosos por "su belleza, por contener formaciones geológicas extraordinarias, regiones y los objetos naturales de interés estético o valor histórico o científico y los lugares donde existen condiciones primitivas".

La Convención de Washington, además tiene otra importancia; es una de las convenciones más citadas en la jurisprudencia, aunque en general no es frecuente que los jueces citen tratados ambientales. ${ }^{35}$

Uno de los casos destacados donde se invoca la Convención de Washington es el caso lago Chungará. En este sentido, Osvaldo Urrutia señala:

...la Corte Suprema señaló en su considerando 13... que: [Las riquezas existentes en los Parques Nacionales no podrán explotarse con fines comerciales...] la paralización ordenada se fundamenta en la existencia de los Convenios Internacionales... Convenciones y Acuerdos que requieren de una interpretación y aplicación cuidadosa de parte del gobierno por estar en juego la fe internacional. ${ }^{36}$

35 Sobre una suerte de activismo judicial verde por la Corte Suprema de Chile, cfr. Cordero, Eduardo, "De la propiedad a las propiedades, la evolución de la concepción liberal de la propiedad", Revista de Derecho de la Pontificia Universidad Católica de Valparaíso, XXXI, Valparaíso, 2o. semestre de 2008, p. XLIX.

36 Urrutia Silva, Osvaldo, "Jurisprudencia nacional, nuevos tribunales ambientales y derecho internacional del medio ambiente", Revista de Derecho, Pontificia Universidad 
Esta revista forma parte del acervo de la Biblioteca Jurídica Virtual del Instituto de Investigaciones Jurídicas de la UNAM

Sin embargo, la jurisprudencia no es definitiva en esta materia; además, es llamativo que la protección del paisaje se construya desde la invocación a la Convención de Washington y no desde la Constitución.

Otro fallo más reciente dictado por la Corte Suprema señala, a propósito de la protección del paisaje:

...procederá a retirar de inmediato todos aquellos residuos sólidos que provengan de los excedentes de las excavaciones y los excedentes de trabajos de urbanización... absteniéndose - asimismo-, de intervenir la zona de protección por valor natural y paisajístico (ZRI-2), manteniendo el sector bajo la cota 9 s.n.m.m en su estado natural... ${ }^{37}$

En Europa, las primeras referencias constitucionales sobre medio ambiente, concretamente sobre la protección del paisaje, se encuentran en Italia, en la Constitución de 1947, donde, como ya señalé, se hace referencia a la tutela del paesaggio, junto al patrimonio histórico y artístico como principios fundamentales de la República. Por otra parte, es en los Estados Unidos donde se desarrolla primariamente el interés por la protección del paisaje. La influencia de Thoreau en esta cuestión es trascendental. ${ }^{38}$

Se debe destacar en este punto, además, que buena parte de los 102 conflictos socioambientales identificados por el Instituto Nacional de Derechos Humanos se producen en regiones reconocidas por su belleza paisajística.

\section{Medio ambiente como cláusula de restricción de derechos}

Señala el artículo 19, núm. 8: “La ley podrá establecer restricciones específicas al ejercicio de determinados derechos o libertades para proteger el medio ambiente".

Católica de Valparaíso, núm. 40, Valparaíso, agosto de 2013, p. 483. Se debe en todo caso reconocer que este criterio no es el que siempre ha operado para la protección de parques naturales; así, es posible ver en el caso Palmar Correntoso, p. 483.

37 Rol 1.021-2013 Corte Suprema, en este caso el recurrente denuncia la intervención de la zona de protección por valor natural y paisajístico, denominada ZRI-2, delimitada por el Plan Regulador Intercomunal, a través del deslizamiento de limos y sedimentos, provocados por movimientos de tierra por parte de los recurridos.

38 Thoureau, Henry David, Walden, "la vida en los bosques", trad. de Jorge Lobato, http://consumoetico.webs.uvigo.es/textos/walden.pdf.

D. R. (C) 2017. UNAM, Instituto de Investigaciones Jurídicas,

Boletin Mexicano de Derecho Comparado, núm. 148, pp. 113-144. 
Esta revista forma parte del acervo de la Biblioteca Jurídica Virtual del Instituto de Investigaciones Jurídicas de la UNAM

Se trata de una norma inusual en la configuración de los derechos fundamentales. Ya se ha dicho que ningún derecho es absoluto. Los derechos fundamentales pueden ser afectados por otros derechos cuando éstos entran en tensión. ${ }^{39}$ Lo llamativo de la norma es que en ella se asegura una protección prima facie en favor del medio ambiente.

En la Constitución, además del artículo 19, núm. 8, en su inciso final, contemplan la posibilidad de restringir derechos para asegurar la protección del medio ambiente:

Artículo 19 núm. 16. La libertad de trabajo y su protección... Ninguna clase de trabajo puede ser prohibida, salvo que se oponga a la moral, a la seguridad o a la salubridad públicas, o que lo exija el interés nacional y una ley lo declare así;

Artículo 19 núm. 23. La libertad para adquirir el dominio de toda clase de bienes, excepto aquellos que la naturaleza ha hecho comunes a todos los hombres o que deban pertenecer a la Nación toda y la ley lo declare así;

Artículo 19 núm. 24. El derecho de propiedad en sus diversas especies sobre toda clase de bienes corporales o incorporales. Sólo la ley puede establecer el modo de adquirir la propiedad, de usar, gozar y disponer de ella y las limitaciones y obligaciones que deriven de su función social. Esta comprende cuanto exijan los intereses generales de la Nación, la seguridad nacional, la utilidad y la salubridad públicas y la conservación del patrimonio ambiental.

Volviendo a la Comisión Ortúzar, a propósito de la restricción de derechos, el presidente de la Comisión señaló que "Le parece incuestionable que estas restricciones van a estar referidas, fundamentalmente, al derecho de propiedad y, quién sabe, si probablemente también al derecho de reunión...". 40

Me parece que la frase final del artículo 19, núm. 8, agrega otro plus a la cuestión que analizamos. El legislador, el juez y todos los poderes del Estado, ante una eventual tensión entre otros derechos y el medio ambiente, no sólo pueden, sino que deben restringirlos, si eso garantiza la protección de este último. Es una solución que, prima facie, se resuelve en favor del medio ambiente. Por eso sostengo que la cuestión ambiental goza de una especial y reforzada protección en la Constitución.

39 También las Constituciones de Rumania (artículo 44.7); Eslovenia (artículo 20.3) introducen este tipo de limitaciones con relación al derecho de propiedad.

40 Acta 186, op. cit. 
Esta revista forma parte del acervo de la Biblioteca Jurídica Virtual del Instituto de Investigaciones Jurídicas de la UNAM

En seguida me centraré, por ser de particular interés, en las limitaciones al derecho de propiedad que derivan de su función social y que se dirigen a asegurar la protección del patrimonio ambiental.

\section{A. Medio ambiente: restricciones, obligaciones y derecho de propiedad}

Las limitaciones al derecho de propiedad se relacionan con la llamada "función social de la propiedad". Sobre esta noción, afirma Luis Cordero Quinzacara

...el propietario tiene el deber y, por tanto, el poder de emplear la cosa que posee en la satisfacción de las necesidades individuales que le son propias, de emplear la cosa para el desarrollo de su actividad física, intelectual y moral, pero también tiene el deber y, por tanto, poder, de emplear la cosa que posee en la satisfacción de necesidades comunes o colectivas. ${ }^{41}$

Estamos ante otro refuerzo del medio ambiente. Esta norma y el deber del Estado de tutelar la preservación de la naturaleza darían lugar, claramente, a la protección reforzada de los elementos naturales del entorno. Mientras el ambiente, en un sentido amplio, sería el contenido del derecho fundamental a vivir en un medio ambiente libre de contaminación.

De esta manera, y concluyendo para este apartado, la cláusula de restricción de derechos es un mecanismo dirigido a la protección del patrimonio natural; es decir, la naturaleza. ${ }^{42}$ Dicho esto, nuevamente debemos resaltar que la norma no ha desarrollado toda su fuerza normativa. Un buen ejemplo para demostrar esta afirmación es el caso Hidroaysén.

Se trata de un proyecto para construir cinco represas en la Patagonia chilena, región conocida por su paisaje de especial valor escénico y ambiental. En este caso, no obstante, el proyecto había sido aprobado en el sistema de evaluación de impacto ambiental. La fuerte oposición de gru-

41 Cordero, Eduardo, "De la propiedad a las propiedades, la evolución de la concepción liberal de la propiedad", Revista de Derecho de la Pontificia Universidad Católica de Valparaíso XXXI, Valparaíso, 2o. semestre de 2008, p. 511.

42 Un planteamiento similar sostiene Rodrigo Guzmán Rosen cuando señala: “sostengo que en sede constitucional se ha querido expresar que el ambiente se conforma únicamente por elementos naturales". Guzmán Rosen, Rodrigo, La regulación constitucional del ambiente en Chile. Aspectos sustantivos y adjetivos. Historia doctrina y jurisprudencia, 2a. ed. actualizada, Santiago Abeledo-Perrot-Legal Publishing, 2010, p. 34.

D. R. (C) 2017. UNAM, Instituto de Investigaciones Jurídicas,

Boletin Mexicano de Derecho Comparado, núm. 148, pp. 113-144. 
Esta revista forma parte del acervo de la Biblioteca Jurídica Virtual del Instituto de Investigaciones Jurídicas de la UNAM

pos ambientalistas y movimientos sociales, incidió para que finalmente el proyecto no se concretara. La decisión final en este caso fue tomada por el Comité de Ministros. Lo llamativo es que en la decisión de retirar la aprobación al proyecto no se incluyó como criterio la valoración del paisaje. ${ }^{43}$

\section{B. El derecho fundamental a vivir en un medio ambiente libre de contaminación}

A diferencia de los deberes de protección, el derecho fundamental a vivir en un medio ambiente libre de contaminación cuenta con una garantía jurisdiccional en la Constitución. Cabe señalar que el recurso de protección ambiental es más restringido que el recurso de protección que garantiza otros derechos constitucionales. El recurso ambiental sólo procede en los casos de afectación concreta y no en casos de amenaza a la afectación del derecho. ${ }^{44}$

De esta manera, no sería objeto de tutela una decisión que no considere el principio preventivo, ${ }^{45}$ porque el principio opera por definición antes de que la afectación se produzca. Se puede afirmar, entonces, que el recurso de protección está destinado a operar cuando el derecho ya sido conculcado y no cuando existe una amenaza que no se ha concretado. También en esta materia encontramos jurisprudencia contradictoria. ${ }^{46}$

43 Cfr. http://wrerw:Lanacion.cl/noticias/economia/energia/dura-derrota-de-hidroaysen-rechazadopor-comite-de-ministros/2014-06-10/111656.html.

44 La regulación general del recurso de protección en el artículo 20 de la Constitución señala: "El que por causa de actos u omisiones arbitrarios o ilegales sufra privación, perturbación o amenaza en el legítimo ejercicio de los derechos y garantías establecidos en el artículo 19, núms. 1..." (las cursivas son nuestras).

45 En esta cuestión señala Pilar Moraga: "La Corte Internacional de Justicia considera al principio preventivo como el «deber de diligencia» que tiene cada Estado sobre su territorio, el cual se operacionaliza a través de la evaluación de impacto ambiental". Cfr. Moraga, Pilar, op. cit., p. 13.

46 Así, por ejemplo, en la causa Rol 6.183 de 2013, la Corte Suprema rechazó el recurso de protección contra el complejo hidroeléctrico Santa María de Coronel de Empresa Colbún, S. A., "por succionar, almacenar y evacuar recursos hidrobiológicos en sistemas de aducción y descarga de agua de mar con que cuenta la empresa para el enfriamiento de sistema de calderas". En este caso, entre otros fundamentos, la Corte Suprema señaló "que a los recurrentes no les asiste un derecho indubitado y los conflictos objeto del recurso. Dicen relación con materias controvertidas por las partes, lo que no se condice con el carácter extraordinario y de tramitación breve que tiene el recurso de protección de garantías constitucionales".

D. R. (C) 2017. UNAM, Instituto de Investigaciones Jurídicas, Boletín Mexicano de Derecho Comparado, núm. 148, pp. 113-144. 
Esta revista forma parte del acervo de la Biblioteca Jurídica Virtual del Instituto de Investigaciones Jurídicas de la UNAM

\section{Contenido y alcance del derecho fundamental a vivir en un medio ambiente libre de contaminación}

La noción "medio" se refiere al hábitat que nos rodea, sea un bosque, el lugar en el que vivimos o trabajamos. Así, por ejemplo, la Corte Suprema confirmó una sentencia de la Corte de Apelaciones de Temuco, por las "serias deficiencias sanitarias del Centro de Cumplimiento Penitenciario de Temuco". En este caso consideró la Corte que "toda persona tiene el derecho a vivir en un ambiente libre de contaminación, garantía que obviamente se extiende al lugar en que ésta presta sus labores". ${ }^{47}$

Esta noción, en una dimensión amplia, también es abordada en la Ley 19.300 (artículo 2o., ll), que define al medio ambiente como "el sistema global constituido por elementos naturales y artificiales de naturaleza física, química o biológica, socioculturales y sus interacciones, en permanente modificación por la acción humana o natural y que rige y condiciona la existencia y desarrollo de la vida en sus múltiples manifestaciones".

Jorge Bermúdez plantea en seguida un debate con cuya solución estoy de acuerdo, mas no con su razonamiento. La cuestión es si el entorno debe ser entendido en un sentido amplio: es decir, si una persona que reside en Santiago puede ver afectado su derecho por la contaminación de las aguas de un río en Aysén (más de $1.600 \mathrm{~km}$ separan a Santiago y Aysén). Bermúdez propone superar la tensión a través de la noción "entorno adyacente"; esto es, para recurrir de protección por la afectación del derecho se requiere que la persona pueda percibir las consecuencias nocivas derivadas de la acción contaminante. Su protección jurisdiccional no alcanzaría a situaciones donde los daños no puedan percibirse. Para Bermúdez, entorno adyacente sería "el lugar necesario para que el individuo se desarrolle... el espacio que él necesita para poder desplegar sus capacidades, en definitiva, el entorno relacionado al individuo...". 48

A pesar de que comparto la conclusión, no debe confundirse al derecho fundamental con su protección. Una cosa es el derecho y otra distinta su tutela jurisdiccional. Todos tenemos derecho a que no se contaminen las aguas de un río en Aysén. Pero si esas aguas son contaminadas, quienes

47 Rol 5.438-2012 Corte Suprema, conociendo de apelación en recurso de protección (acogido parcialmente) contra la Dirección Regional de Gendarmería de la Araucanía por serias deficiencias sanitarias en el Centro de Cumplimiento Penitenciario de Temuco.

48 Bermúdez, op. cit., p. 123.

D. R. (C) 2017. UNAM, Instituto de Investigaciones Jurídicas,

Boletin Mexicano de Derecho Comparado, núm. 148, pp. 113-144. 
Esta revista forma parte del acervo de la Biblioteca Jurídica Virtual del Instituto de Investigaciones Jurídicas de la UNAM

poseen legitimación activa para reclamar por vía del recurso de protección son las personas que se encuentran en el entorno adyacente.

Confirmando esta perspectiva, la Tercera Sala de la Corte Suprema consideró que los recurrentes, que comparecieron en representación de la Fundación Patrimonio Nuestro, no demostraron poseer un interés directo e inmediato en la acción que invocaron:

El recurso de protección no constituye una acción popular, por lo que debe demostrarse por quien lo impetra interés jurídico en su resultado... Los recurrentes han invocado como derecho constitucional tutelado el consagrado en el núm. 8 del artículo 19 de la Carta Fundamental, sin que hayan demostrado un interés directo e inmediato en la protección de la garantía que invocan, razón por la cual carecen de legitimación activa para interponer este recurso de protección... ${ }^{49}$

En cuanto a la noción "libre de contaminación", en la Comisión Ortúzar se dijo en este punto: el medio ambiente siempre está contaminado. Para Jaime Guzmán, "lo que se desea evitar es la contaminación peligrosa para el ser humano e inconveniente para la sociedad". ${ }^{50}$

Una perspectiva amplia de la cuestión también se sostuvo por el comisionado Diez, cuando señaló: “...quienes producen contaminación ambiental no son sólo los pescadores con sus motores a bencina, en los lagos y embalses, o los que botan basuras... Hay una contaminación ambiental que es, seguramente, mucho más grandes: la producida por las industrias, por los elementos de calefacción, etcétera...". ${ }^{51}$

¿Qué entendemos por "contaminación”, en la jurisprudencia? Para los jueces, la contaminación puede producirse, entre otras razones, por malos olores, por ruidos y por sobreexposición lumínica.

Así, por ejemplo, ha dicho la Corte Suprema, "los recurrentes - vecinos domiciliados en el sector aledaño - deben soportar día a día esos hedores, impactando ello en su calidad de vida, afectando su integridad síquica, por lo que a juicio de esta Corte se vulneran las garantías constitucionales de los mismos". ${ }^{52}$

\footnotetext{
49 Rol 7677-2013, Corte Suprema.

50 Acta 186, op. cit.

51 Idem.

52 En este caso los recurrentes señalaron: "Recurrentes señalan que la recurrida es propietaria y responsable de la Planta de Tratamientos de Aguas Servidas de Los Ángeles, 
Esta revista forma parte del acervo de la Biblioteca Jurídica Virtual del Instituto de Investigaciones Jurídicas de la UNAM

También la contaminación por ruidos forma parte de las posibles afectaciones al derecho. En este sentido, ha dicho la Corte Suprema:

...se hace necesario proteger los derechos del recurrente y su familia, de una manera eficaz, impidiendo que se sigan vulnerando sus derechos, cuestión que sólo se logra decretando que el establecimiento de la sociedad recurrida debe suspender su funcionamiento hasta que obtenga de la Autoridad Sanitaria un certificado que acredite que los trabajos realizados son suficientes para aislar los ruidos emitidos y que éstos se ajustan al máximo permitido en relación al lugar y horario de funcionamiento del local. ${ }^{53}$

\section{Lo mismo ha ocurrido por contaminaciones lumínicas. Dice la Corte} Suprema:

Que el Departamento de Salud Ocupacional del Ministerio de Salud, en su informe de..., expresa que "Los niveles de contaminación lumínica (iluminancia vertical en lux) al interior de los departamentos evaluados... se encuentra por sobre el límite señalado por el criterio de referencia para una zona de alto brillo y horario restrictivo, mientras que sólo uno de ellos (departamento 1, piso 2o.) se encuentra bajo el límite del horario menos restrictivo de 1.2 lux... ${ }^{54}$

También la Ley 19.300 aborda el concepto "medio ambiente libre de contaminación", y lo define como "aquél en el que los contaminantes se encuentran en concentraciones y períodos inferiores a aquéllos susceptibles de constituir un riesgo a la salud de las personas, a la calidad de vida de la población, a la preservación de la naturaleza o a la conservación

ubicada a $2 \mathrm{~km}$., al poniente de esta ciudad, en el sector conocido como Lomas de Santa María, complejo que ha sido sindicado como responsable de la emisión de olores pestilentes y nauseabundos semejantes a excremento y aguas servidas, que han sido perceptibles por habitantes del sector poniente de la ciudad de Los Ángeles, en particular por los recurrentes los cuales son habitantes de las viviendas aledañas de la Planta antes singularizada". Rol 7099-2012, Corte Suprema.

53 Rol 9047-2012, Corte Suprema, Recurso de protección acogido parcialmente por saturación de ruidos.

54 Rol 3035-2012, Corte Suprema, Recurrente solicita se adopten medidas de resguardo por verse afectados derechos que la Constitución Política le garantiza, en los números 1 y 8 de su artículo 19; con motivo de la instalación de un letrero publicitario en pantalla LED en la parte superior del edificio mencionado, cuyas luminancias invaden el ámbito del edificio de su comunidad.

D. R. (C) 2017. UNAM, Instituto de Investigaciones Jurídicas,

Boletin Mexicano de Derecho Comparado, núm. 148, pp. 113-144. 
Esta revista forma parte del acervo de la Biblioteca Jurídica Virtual del Instituto de Investigaciones Jurídicas de la UNAM

del patrimonio ambiental". Sobre este concepto, la doctrina plantea sus críticas, pues la definición conecta al derecho con el derecho a la salud. ${ }^{55}$

Comparto las críticas. En la definición legal se vacía de contenido al derecho fundamental. En efecto, al asociarlo al derecho a la salud, bastaría con que la persona afectada se remita al derecho a la salud, perdiendo sentido el derecho fundamental ambiental. Quizá la norma incurre en este problema por la complejidad que implica definir el umbral de acceso a la tutela del derecho.

Llegados a este punto, me parece que desde una perspectiva sistemática, el objeto del derecho fundamental a vivir en un medio ambiente libre de contaminación consiste en una garantía para que las personas disfruten de un entorno que asegure su bienestar y su calidad de vida. Se trata de una noción amplia que deberá determinarse caso a caso. En el mismo sentido, Bordalí asevera: "es posible afirmar que el objeto de este derecho fundamental es garantizar que las personas puedan vivir en términos de calidad o con bienestar en relación con el ambiente en que viven". ${ }^{56}$

En cuanto al titular de este derecho, se trata de un derecho egocéntrico. La Constitución asegura a todas las personas el derecho a vivir en un medio ambiente libre de contaminación. La Constitución no garantiza un derecho cuyo titular sea el ambiente o el entorno, al que en cambio coloca como objeto de protección.

¿Sólo las personas naturales son titulares de este derecho? La doctrina ha entendido que el uso de la expresión vivir no incluiría a las personas jurídicas, que no tendrían legitimación activa para recurrir a través del recurso de protección. Sin embargo, una persona jurídica podría eventualmente recurrir de protección en representación de los intereses de la comunidad.

¿Qué dice la jurisprudencia? No es posible configurar una única perspectiva en esta cuestión. Aunque la jurisprudencia se ha inclinado por reconocer que se trata de un derecho individual, pero a la vez colectivo, reconociendo con ello la legitimación activa de organizaciones y personas

55 Nogueira, Humberto, "Revista Jurídica Justicia Ambiental revista de Derecho Ambiental de la Fiscalía del Medio Ambiente FIMA", Estudios Constitucionales, año 7, núm. 2, 2009, p. 470.

56 Bordalí, Andrés, "La función social como delimitación interna e inherente del derecho de propiedad y la conservación del patrimonio ambiental", Revista de Derecho, núm. especial, agosto de 1998, p. 118.

D. R. (C) 2017. UNAM, Instituto de Investigaciones Jurídicas, Boletín Mexicano de Derecho Comparado, núm. 148, pp. 113-144. 
Esta revista forma parte del acervo de la Biblioteca Jurídica Virtual del Instituto de Investigaciones Jurídicas de la UNAM www.juridicas.unam. $m x$

jurídicas para interponer el recurso de protección, también encontramos casos donde se ha negado este carácter.

Veamos algunos casos. En recurso de protección conocido por la Corte Suprema, ésta señaló:

...la recurrente - Grupo de Acción Ecológica Chinchimén-, se encuentra legitimada para recurrir por esta vía, en cuanto persona jurídica que es, habida consideración que si bien a través del recurso de protección resulta posible amparar derechos fundamentales de los individuos, nuestros tribunales también han dado cabida a legitimaciones de otra naturaleza reduciendo el margen de exigencia en la acreditación de la titularidad de la acción, resultando también útil consignar que el derecho definido en el artículo 19, núm. 8 de la Carta es de índole individual, pero, al mismo tiempo, también social... conforma asimismo un derecho social, por cuanto resguarda bienes jurídicos de carácter colectivo que deben ser protegidos por el Estado, para lo cual la Carta le exige el cumplimiento de ciertas tareas, según lo que indica la segunda oración del inciso 1 del núm $8 .{ }^{57}$

\section{Medio AMbiente Y TRATAdos RATIFICAdos EN CHILE ${ }^{58}$}

Antes que en el derecho constitucional, es en el derecho internacional donde primero se desarrollan compromisos para la protección del medio ambiente. Chile ha sido extraordinariamente activo en la ratificación de instrumentos internacionales de contenido ambiental.

Antes de analizar los distintos instrumentos que se han ratificado en este ámbito, es muy importante tener presente que en Chile la norma que se refiere a los derechos provenientes de tratados internacionales ratifica-

57 Rol 1.021-2013, Corte Suprema. "El recurrente denuncia la intervención de la zona de protección por valor natural y paisajístico, denominada ZRI-2, delimitada por el Plan Regulador Intercomunal, a través del deslizamiento de limos y sedimentos, provocados por movimientos de tierra por parte de los recurridos".

58 Agradezco a Marcela Molina, colaboradora en su calidad de tesista, del Proyecto Fondecyt de iniciación: Estudio sobre los derechos y obligaciones que reconoce y asume el Estado chileno en materia ambiental desde una perspectiva constitucional, núm. 11140270. También en la recopilación de jurisprudencia agradezco a Manuel Yañez; Erik Jaña, Rodrigo Poblete, Victoria Schmeda, y por sus contribuciones en la recopilación de información, a Camila Venegas.

D. R. (C) 2017. UNAM, Instituto de Investigaciones Jurídicas,

Boletin Mexicano de Derecho Comparado, núm. 148, pp. 113-144. 
Esta revista forma parte del acervo de la Biblioteca Jurídica Virtual del Instituto de Investigaciones Jurídicas de la UNAM

dos y vigentes es el artículo 5o., inciso 2, de la Constitución. ${ }^{59}$ La norma ha traído un favorable dinamismo al sistema de fuentes del derecho. Incluso, y aunque la polémica sobre el valor de los tratados internacionales no ha sido superada, existe un consenso relativo en orden a incorporar tratados internacionales en la elaboración de los argumentos de los jueces; esto es especialmente llamativo en lo que se refiere al catálogo de derechos. Ahora bien, en la materia que analizamos, se debe tener presente que la norma hace referencia a los derechos esenciales que emanan de la naturaleza humana; desde luego, no es claro que los tratados de contenido ambiental formen parte de esta categoría. ${ }^{60}$

Sin ánimo de exhaustividad, dado que no se han elaborado registros definitivos por las autoridades nacionales, desde 1925 hasta 2014, Chile ha ratificado 93 tratados/protocolos y enmiendas en materia ambiental. En seguida presentaré una perspectiva global de esos instrumentos. Debo destacar, nuevamente, que el entusiasmo por participar de estos compromisos no ha tenido consecuencias directas en la protección del medio ambiente.

De esos 93 instrumentos, organizados conforme su objeto: sobre protección marítima, se han ratificado veintitrés instrumentos; mientras que dieciséis dicen relación con la conservación de flora y fauna; sobre cambio climático y protección de la capa de ozono se han ratificado once; referidos a la Antártica, ocho; sobre agricultura y alimentación, siete; sobre armas nucleares, siete, y sobre contaminación, seis.

A pesar de este activo compromiso internacional con la protección del medio ambiente, no se deben perder de vista los compromisos concretos que se asumen en este ámbito; ya el derecho internacional de por sí se construye con base en una cierta vaguedad. ${ }^{61}$ Veamos en seguida algunos

59 "Artículo 5o. La soberanía reside esencialmente en la Nación. Su ejercicio se realiza por el pueblo a través del plebiscito y de elecciones periódicas y, también, por las autoridades que esta Constitución establece. Ningún sector del pueblo ni individuo alguno puede atribuirse su ejercicio. El ejercicio de la soberanía reconoce como limitación el respeto a los derechos esenciales que emanan de la naturaleza humana. Es deber de los órganos del Estado respetar y promover tales derechos, garantizados por esta Constitución, así como por los tratados internacionales ratificados por Chile y que se encuentren vigentes.

60 Galdámez, Liliana, "La relación...".

61 En este sentido, afirma Carrillo Salcedo: "En el sistema jurídico internacional, por consiguiente, las situaciones y las obligaciones de los sujetos difieren según el Estado que se considere, ya que cada Estado aprecia unilateral y subjetivamente el alcance de sus obli- 
Esta revista forma parte del acervo de la Biblioteca Jurídica Virtual del Instituto de Investigaciones Jurídicas de la UNAM

ejemplos de responsabilidades que apenas implican obligaciones concretas:

El Convenio para la Protección del Medio Ambiente y la Zona Costera del Pacifico Sudeste 1981-1986, ratificado por Augusto Pinochet, entre sus compromisos señala:

1. Las Altas Partes Contratantes se esforzarán, ya sea individualmente o por medio de la cooperación bilateral o multilateral, en adoptar las medidas apropiadas de acuerdo a las disposiciones del presente Convenio y de los instrumentos complementarios en vigor de los que sean parte, para prevenir, reducir y controlar la contaminación del medio marino y zona costera del Pacífico Sudeste y para asegurar una adecuada gestión ambiental de los recursos naturales.

En una dirección de mayor compromiso, podemos identificar al Convenio de Proscripción de Pruebas Nucleares 1963-1965, donde los Estados se comprometen a "prohibir, impedir y a no realizar ninguna explosión de prueba de armas nucleares ni ninguna otra explosión nuclear en lugar alguno que estuviere bajo su jurisdicción o control" (artículo 1.1). También, el Convenio de Basilea sobre el Control de los Movimientos Transfronterizos de los Desechos Peligrosos y su Eliminación 1989-1992, donde los Estados

...prohibirán o no permitirán la exportación de desechos peligrosos y otros desechos a las Partes que hayan prohibido la importación de esos desechos... Toda Parte adoptará las medidas jurídicas, administrativas y de otra índole que sean necesarias para aplicar y hacer cumplir las disposiciones del presente Convenio, incluyendo medidas para prevenir y reprimir los actos que contravengan el presente Convenio.

Junto a esta prolífica multiplicación de tratados internacionales, que como dijimos, suelen establecer compromisos blandos y a veces ino-

gaciones. Ello trae consigo que, en virtud del principio de equivalencia de las pretensiones, derivado de la igualdad soberana de los Estados, el orden jurídico internacional presente como una de sus características la de aparecer como una multiplicidad de representaciones subjetivas y divergentes; en consecuencia, el sistema internacional no es un conjunto coherente sino, más bien, un rompecabezas de alegaciones y pretensiones subjetivas que tienen, todas ellas, simplemente valor de presunciones". Carrillo Salcedo, Juan Antonio, "Derechos humanos y derecho internacional", Isegoria, núm. 22, 2000, p. 71.

D. R. (C) 2017. UNAM, Instituto de Investigaciones Jurídicas,

Boletin Mexicano de Derecho Comparado, núm. 148, pp. 113-144. 
Esta revista forma parte del acervo de la Biblioteca Jurídica Virtual del Instituto de Investigaciones Jurídicas de la UNAM

$\operatorname{cuos}^{62}{ }^{6}$ en el ámbito del derecho internacional otras obligaciones se han suscrito en el ámbito de conferencias y declaraciones internacionales. Este conjunto de acuerdos se asimila a la noción soft law; es decir, normas no vinculantes, que sin embargo suelen ser una importante fuente a la hora de valorar la importancia del medio ambiente, y particularmente en lo que se refiere a los principios ambientales. Estos instrumentos son en la práctica más usados por los jueces y a través de la invocación de los principios que contienen, adquieren una relevancia que incrementa su fuerza normativa a pesar de la debilidad de la fuente que los contiene, eso porque son frecuentemente invocados por los jueces en sus razonamientos como un elemento central de su conclusión.

Por otra parte, es importante destacar también otros tratados que no son de carácter estrictamente ambiental, como el Convenio 169 sobre Pueblos Indígenas y Tribales en Países Independientes, que ha sido frecuentemente invocado en varios sentidos, especialmente en lo que se refiere al cumplimiento del deber de consulta. ${ }^{63}$

Algunos ejemplos de estos destacados y estratégicos documentos son: Declaración de la ONU sobre Medio Humano, Estocolmo, 1972, del 5 al 16 de junio 1972; la Declaración de Río sobre el Medio Ambiente y el Desarrollo, "Cumbre de la Tierra", del 3 al 14 de junio de 1992, Brasil; la Declaración Río+20 "El Futuro Que Queremos", del 20 al 22 de junio de 2012; la Declaración de la ONU sobre los Derechos de los Pueblos Indígenas, de Nueva York, 13 de septiembre de 2007, reconoce la plena capacidad de goce de derechos de los pueblos indígenas, así como su libertad e igualdad con todos los otros pueblos. La libre determinación de los pueblos como eje fundamental de su desarrollo (artículos 3o., 4o., 5o.). ${ }^{64}$

En este ámbito, por otra parte, se debe dar una especial relevancia al Acuerdo de París sobre Cambio Climático, de 2015 (COP21 de la Convención Marco de Naciones Unidas sobre Cambio Climático). En el con-

62 Con relación a los Amunas, Acuerdos Multilaterales sobre Medio Ambiente, y sus limitaciones para su aplicación directa en el ordenamiento interno, véase Fuentes Torrijo, Ximena y Arístegui Sierra, Juan Pablo, “ ¿Nos basta con los convenios internacionales para una adecuada regulación del uso sustentable de los recursos naturales?", en Aranda, Jorge et al. (ed.), Actas de las Fornadas de Derecho Ambiental Recursos Naturales: ¿sustentabilidad o sobreexplotación?, Santiago, Centro de Derecho Ambiental, Facultad de Derecho, Universidad de Chile-Legal Publishing-Thomson Reuters, 2014, p. 102.

63 Corte Suprema, Rol 5.339-2013, Corte Suprema, Rol 3.010-2013.

64 Urrutia Silva, Osvaldo, op. cit., pp. 489 y ss.

D. R. (C) 2017. UNAM, Instituto de Investigaciones Jurídicas, Boletín Mexicano de Derecho Comparado, núm. 148, pp. 113-144. 
Esta revista forma parte del acervo de la Biblioteca Jurídica Virtual del Instituto de Investigaciones Jurídicas de la UNAM

texto de este acuerdo, los países adquirieron compromisos voluntarios de limitación de emisiones en pro de controlar el aumento de la temperatura media mundial a uno coma cinco grados centígrados. ${ }^{65}$ A efectos de este compromiso voluntario, los países presentaron lo que se denominó, Intended Nationally Determined Contribution to Mitigation. Así, en el caso de Chile se ha elaborado un compromiso denominado Contribución Nacional Tentativa de Chile (INDG) para el Acuerdo Climático, París, 2015 ${ }^{66}$ A pesar de la importancia de la instancia, no se puede perder de vista el lenguaje que utiliza, Contribución tentativa. Como se señaló antes, se trata de compromisos que se cumplirán en la medida de lo posible.

Como se ha visto, la apertura del Estado chileno a la suscripción de acuerdos internacionales especialmente concebidos para la protección del entorno y el control de actividades contaminantes no ha reforzado de manera significativa la tutela del medio ambiente. Ya no nos referimos a tratados que reconocen derechos fundamentales; su objeto es principalmente la protección del entorno y los elementos naturales del ambiente, que, recordando las estadísticas que mencionaba al inicio, no han incrementado la ya debilitada fuerza normativa de la Constitución en esta materia.

\section{REFLEXIONES FINALES}

La protección constitucional del medio ambiente en el derecho chileno, pese a toda su amplitud, ha sido más nominal que concreta. La presión sobre el medio ambiente ha cedido frente al modelo de desarrollo. Así lo demuestran los informes nacionales, como el de Conflictos Socioambientales del INDH, e internacionales, como el de la OCDE. El orden público económico que la Constitución también garantiza ha extendido sus dominios

65 “a) Chile is committed to reduce its CO2 emissions per GDP unit by 30\% below their 2007 levels by 2030, considering a future economic growth which allows to implement adequate measures to reach this commitment... a) Chile has committed to the sustainable development and recovery of 100,000 hectares of forest land, mainly native, which will account for greenhouse gas sequestrations and reductions of an annual equivalent of around 600,000 of CO2 as of 2030. This commitment is subject to the approval of the Native Forest Recovery and Forestry Promotion Law", en http://wrew 4.unfccc.int/Sub missions/INDC/Published\%20Documents/Chile/1/INDC\%20Chile\%20english\%20version.pdf.

66 Disponible en http://wrwro4.unfccc.int/Submissions/INDC/Published\%20Documents/Chile /1/Chile\%20INDC\%20FINAL.pdf.

D. R. (C) 2017. UNAM, Instituto de Investigaciones Jurídicas,

Boletin Mexicano de Derecho Comparado, núm. 148, pp. 113-144. 
Esta revista forma parte del acervo de la Biblioteca Jurídica Virtual del Instituto de Investigaciones Jurídicas de la UNAM

por sobre los deberes de protección, especialmente concebidos para tutelar la preservación de la naturaleza. Es como si la norma estuviera allí, pero no hubiera sido vista, como si un manto la hubiera cubierto. Claramente la Constitución de 1980 ha sido superada por la práctica, y su origen no democrático deviene en la desafectación de su contenido.

Fíjese los conflictos socioambientales a que hacía referencia al inicio del trabajo; buena parte de ellos se relacionan con áreas estratégicas de nuestro modelo de crecimiento económico: la minería y actividades extractivas afines, los crecientes requerimientos por dotar de fuentes de energía que sostengan no sólo la vida de las ciudades, sino también a las empresas de la minería que requieren esas fuentes para seguir creciendo. La ecuación medio ambiente-crecimiento económico no ha sido resuelta desde la Constitución. Ha sido zanjada fuera de la Constitución.

Si bien en la década de los setenta ya se había alertado sobre los límites del crecimiento, el país tuvo que recorrer su propio camino hacia el desarrollo para constatar la veracidad de esos límites. Ahora, de cara a la futura Constitución, el desafío es proponer una discusión responsable que tenga presente qué significa preservar el entorno, crecer de una manera sostenible y sus consecuencias.

Desde la perspectiva del derecho internacional, la laxitud de los compromisos que lo caracterizan se expresa en una doble debilidad: por una parte, el contenido de las obligaciones, que es más simbólica que concreta, más cargada de buenas intenciones que de obligaciones firmes, supervisadas; por otra parte, el cuantioso volumen de compromisos asumidos por el país no tiene efectos concretos medibles y contrastables. Es llamativo que sean los instrumentos menos vinculantes los que tengan más cabida en la jurisprudencia; su influencia en la aplicación de principios ambientales ha sido un aporte en la resolución de casos concretos.

Finalmente, muy al inicio de esta investigación, no alcancé a predecir que la norma, su densidad y alcance, eran bastante mayores que los que había logrado anticipar. Las conclusiones a las que acabo de referirme me llevan a plantear que la cuestión ambiental en la nueva Constitución debe ser tomada en serio, debe ser cuidadosamente analizada, su desarrollo posterior debe ser un compromiso de Estado, lo que se acuerde ha de ser entendido producto del consenso y, por sobre todo, debe ser una respuesta consciente de los desafíos que nuestro país y la región enfrentan y enfrentarán en las próximas décadas. 
Esta revista forma parte del acervo de la Biblioteca Jurídica Virtual del Instituto de Investigaciones Jurídicas de la UNAM

\section{BIBLIOGRAFÍA}

República de Chile, "Actas Oficiales de la Comisión Constituyente", sesión 186 de 9 de marzo de 1976, t. V, http://wrwr.bcn.cl/lc/cpolitica/ actas_oficiales-r.

Alexy, Robert, Epílogo a la Teoría de los derechos fundamentales, Madrid, Centro de Estudios Constitucionales, 1993.

AldunATE LizANA, Eduardo, "Interpretación constitucional y decisión política", Revista de Derecho de la Universidad Católica de Valparaíso, XV, 1993-1994.

Astorga Jorquera, Eduardo, Derecho ambiental. Parte general, Santiago, Abeledo-Perrot-Legal Publishing-Thompson Reuters, 2012.

AtienzA, Manuel, "Los límites de la interpretación constitucional. De nuevo sobre los casos trágicos", edición digital a partir de Isonomía. Revista de Teoría y Filosofia del Derecho, núm. 6, de abril de 1997, Biblioteca virtual Miguel de Cervantes, 2005.

Ávila SANTA MARÍA, Ramiro, "El derecho de la naturaleza: fundamentos", Repositorio Institucional del Organismo Académico de la Comunidad Andina CAN, Universidad Andina Simón Bolivar, 2010.

Bermúdez Soto, Jorge, Fundamentos de derecho ambiental, 2a. ed., Ediciones Universitarias de Valparaíso, Pontificia Universidad Católica de Valparaíso, 2015.

Bustos, Beatriz et al., Ecología politica en Chile. Naturaleza, propiedad, conocimiento y poder, Santiago, Editorial Universitaria, 2015

Bordali Salamanca, Andrés, "La función social como delimitación interna e inherente del derecho de propiedad y la conservación del patrimonio ambiental", Revista de Derecho, núm. especial, agosto de 1998.

-, Tutela jurisdiccional del medio ambiente, Santiago, Editorial Fallos del Mes Ltda, 2004.

Carrillo SAlcedo, Juan Antonio, "Derechos humanos y derecho internacional”, Isegoria, núm. 22, 2000.

COMISIÓN ECONÓMICA PARA AMÉRICA LATINA Y EL CARIBE (CEPAL)ORGANIZAGión PARA LA COOPERACIÓN Y EL DESARROLlO EGONÓMICOS (OCDE), Evaluaciones del desempeño ambiental: Chile 2016, Santiago, 2016.

CONTRIBUCiÓn NAGIONAL TENTATIVA DE ChILE (INDG) para el acuerdo climático, París, 2015.

D. R. (C) 2017. UNAM, Instituto de Investigaciones Jurídicas,

Boletin Mexicano de Derecho Comparado, núm. 148, pp. 113-144. 
Esta revista forma parte del acervo de la Biblioteca Jurídica Virtual del Instituto de Investigaciones Jurídicas de la UNAM

CORDERO QUinZaCARA, Eduardo, "De la propiedad a las propiedades, la evolución de la concepción liberal de la propiedad", Revista de Derecho de la Pontificia Universidad Católica de Valparaíso, XXXI, Valparaíso, 20. semestre de 2008.

De Sousa Santos, Boaventura, El milenio huérfano, Bogotá, Trotta Ilsa, 2005.

Diccionario de ecología, Buenos Aires, Valleta Ediciones, 2010.

Diez Picazo, Luis, Sistema de derechos fundamentales, Navarra, Aranzadi, 2005.

GALDAMEZ ZELADA, Liliana "Derechos, garantías y principios ambientales en una nueva Constitución", en CHIA, Eduardo y QUEZADA, Flabio (eds.), Propuestas para una nueva Constitución (originada en democracia), Santiago, Instituto Igualdad-Facultad de Derecho, Universidad de ChileFriedrich Eber-Stiftung, 2015.

, "La relación entre el derecho internacional de los derechos humanos y el derecho interno en el ordenamiento chileno y la Constitución material", en NoGUEIRA, Humberto (coord.), Bases de la institucionalidad realidad y desafios, Santiago, Librotecnia, 2015.

GuZMán Rosen, Rodrigo, La regulación constitucional del ambiente en Chile. Aspectos sustantivos y adjetivos. Historia, doctrina y jurisprudencia, Santiago, Abeledo-Perrot, 2010.

Estenssoro SAavedra, Fernando, Historia del debate ambiental en la politica mundial 1945-1992. La perspectiva latinoamericana, Santiago, Instituto de Estudios Avanzados, Universidad de Santiago, 2014.

FERnÁndez Rodríguez, Carmen, La protección del paisaje. Un estudio de derecho español y comparado, Madrid, Marcial Pons, 2007.

Fuentes Torrijo, Ximena y Artistegui Sierra, Juan Pablo, “ ¿Nos basta con los convenios internacionales para una adecuada regulación del uso sustentable de los recursos naturales?", en ARANDA, Jorge et al. (eds.), Actas de las Fornadas de Derecho Ambiental Recursos Naturales: ¿'sustentabilidad o sobre explotación?, Santiago, Centro de Derecho Ambiental, Facultad de Derecho Universidad de Chile-Legal Publishing-Thomson Reuters, 2014.

Mapa de Conflictos Socioambientales en Chile, Instituto Nacional de Derechos Humanos, http://bibliotecadigital.indh.cl/bitstream/handle $/ 123456789 / 478 /$ mapa-conflictos.pdf? sequence $=4$. 
Esta revista forma parte del acervo de la Biblioteca Jurídica Virtual del Instituto de Investigaciones Jurídicas de la UNAM

MORAGA, Pilar, "Análisis de la aplicación principio precautorio en el marco jurídico chileno", en MORAGA, Pilar et al., El principio precautorio en el derecho comparado, Santiago, LOM, 2015.

Nogueira Alcalá, Humberto, "Revista Jurídica Justicia Ambiental revista de Derecho Ambiental de la Fiscalía del Medio Ambiente FIMA", Estudios Constitucionales, año 7, núm. 2, 2009.

RODRÍGUEz PUERTO, Manuel Jesús, Interpretación, derecho ideología. La aportación de la hermenéutica jurídica, Granada, Comares, 2011.

Palomino-Schalscha, Marcela, "Ejercitando poder en tiempos neoliberales: resistencia, co modificación y emprendimiento en Alto Biobío", en Bustos Beatriz et al., Ecología y política en Chile. Naturaleza, propiedad, conocimiento y poder, Santiago, Editorial Universitaria, 2015.

Thoureau, Henry David, Walden la vida en los bosques, trad. de Jorge Lobato, http://consumoetico.webs.uvigo.es/textos/walden.pdf.

SERRANO MORENO, José Luis, Ecología y derecho: principios de derecho ambiental y ecología jurídica, Granada, Comares, 1992.

Simon YARZA, Fernando, Medio ambiente y derechos fundamentales, Madrid, Centro de Estudios Políticos y Constitucionales, 2012.

URrutia Silva, Osvaldo, "Jurisprudencia nacional, nuevos tribunales ambientales y derecho internacional del medio ambiente", Revista de Derecho, Pontificia Universidad Católica de Valparaíso, Valparaíso, núm. 40, agosto de 2013.

\section{Jurisprudencia}

Rol 5.339-2013, Corte Suprema.

Rol 1.021-2013, Corte Suprema.

Rol 18-98, Corte Suprema.

Rol 6.183, Corte Suprema.

Rol 5.438-2012, Corte Suprema.

Rol 7099-2012, Corte Suprema.

Rol 9047-2012, Corte Suprema.

Rol 3010-2013, Corte Suprema.

Rol 3035-2012, Corte Suprema.

Rol 5.339-2013, Corte Suprema.

Rol 1.021-2013, Corte Suprema.

Rol 3929-2013, Corte Suprema.

Rol 7677-2013, Corte Suprema.

D. R. (C) 2017. UNAM, Instituto de Investigaciones Jurídicas,

Boletín Mexicano de Derecho Comparado, núm. 148, pp. 113-144. 